УДК 553.98.048-047.58

\title{
ПОСТРОЕНИЕ ТРЕХМЕРНЫХ МОДЕЛЕЙ НЕФТЕНАСЫЩЕННОСТИ. ОСНОВНЫЕ ПРОБЛЕМЫ И ПОДХОДЫ К ИХ РЕШЕНИЮ
}

\author{
Белкина Валентина Александровна' ${ }^{1}$ \\ belkinava@tyuiu.ru
}

\section{Антипин Ярослав Олегович1, 0000-9015@rambler.ru}

\author{
Забоева Александра Александровна', \\ Alexandra.zaboeva@gmail.com \\ 1 Тюменский индустриальный университет, \\ Россия, 625000, г. Тюмень, ул. Володарского, 38.
}

\begin{abstract}
Актуальность развития методов построения трехмерных моделей начальной нефтенасыщенности обусловлена широким использованием их при решении важнейших задач нефтегазопромысловой геологии: подсчета запасов, проектирования и управления разработкой. Точность решения этих задач, в значительной степени обусловленная адекватностью и детальностью трехмерных моделей начальной нефртенасыщенности, позволяет заметно повысить эфрфективность извлечения углеводородов.

Цель: проанализировать современное состояние алгоритмической и информационной базы трехмерного моделирования начальной нефртенасыщенности, выявить основные проблемы и наиболее перспективные направления их развития, позволяющие повысить их точность.

Методы интерполяции и аппроксимации: детерминированные и стохастические, основанные на двух концепциях теории нефртегазонакопления: антиклинально-гравитационной и относительно недавно появивщейся капиллярно-гравитационной. Для различных геологических ситуаций эти методы модифрицируются способами использования широкого набора косвенной и априорной информации.

Результаты. Выявлены основные возможности повышения точности трехмерных моделей начальной нефртенасьщенности. Во-первых, это создание методов, учитывающих наличие водонефтянных переходных зон, характерных для терригенных полимиктовых пород-коллекторов. Во-вторых, создание дискретно-непрерывных моделей, например, с классификацией по пористости. В этом подходе область моделирования разбивается на отдельные части, в каждой из которых используются свои тренды (одномерные, двумерные и трехмерные). Построение трендов основано на всем комплексе имеющейся эмпирической информации: данных РИГИС, гидродинамических исследований и результатах капиллярометрических исследований. Проклассифицированы способы проверки качества исходных данных и адекватности построенных моделей. Приведены конкретные алгоритмы создания моделей по двум наиболее перспективным направлениям развития алгоритмической базы трехмерного моделирования начальной нефртенасьщенности.
\end{abstract}

\section{Ключевые слова:}

Начальная нефтенасыщенность, трехмерная модель, переходная водонефтяная зона, методы моделирования, косвенная информация, капиллярные силы.

\section{Введение}

Решение большинства геологических задач основано на моделях. В этой ситуации точность решения задач напрямую зависит от адекватности и детальности модели. За последние 15-20 лет трехмерное геологическое моделирование (3D ГМ) стало обязательным при подсчете запасов, проектировании и управлении разработкой. Наиболее сложной, и по этой причине зачастую недостаточно точно решаемой, частью 3D ГМ является трехмерная модель начальной нефтенасыщенности $\left(K_{\text {нн }}\right)$. Изучению закономерностей изменения начальной нефтенасыщенности в объеме пород-коллекторов посвящено большое число исследований [1-8].

При двухфазном насыщении пород-коллекторов «нефтяной пласт представляет собой высокодисперсную систему с большой поверхностью границ раздела фаз и огромным скоплением капиллярных каналов, в которых движутся взаимно нерастворимые жидкости, образующие мениски на границе раздела фаз. Законо- мерности движения нефти и воды в пласте и их взаимные вытеснения в значительной степени определяются капиллярными и молекулярно-поверхностными явлениями, происходящими на поверхности контакта взаимодействующих фаз» [9. С. 5]. Следовательно, ме-

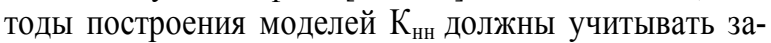
кономерности литологического, фильтрационноемкостного строения и фильтрации флюидов в пласте. Отметим, что в процессе разработки залежей значение нефтенасыщенности $\left(k_{\mathrm{H}}\right)$ изменяется. В данной статье речь идет о коэффициенте начальной нефтенасыщенности $\left(k_{\text {нн }}\right)$.

Анализ методов моделирования проведен только для нефтяных залежей с двухфазным характером насыщения, то есть насыщенных только нефтью и водой. Методы моделирования нефтегазовых и газонефтяных объектов еще заметно более сложны, и пока разработки в этом направлении только начинаются.

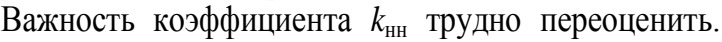
Во-первых, он является подсчетным параметром, вовторых, используется при проектировании и регулиро- 
вании процессов разработки. Использование его в виде трехмерной модели дает более детальное и адекватное описание геологического объекта, что позволяет поднять решение перечисленных задач на качественно новый уровень. Повышение точности моделей начальной нефтенасыщенности - один из важнейших факторов, обеспечивающих наиболее полное возможное извлечение нефти из продуктивных пластов.

\section{Геолого-геофизические предпосылки трехмерных моделей начальной нефтенасыщенности}

В настоящее время широко распространены две концепции теории нефтегазонакопления: антиклинально-гравитационная (АГК) и относительно недавно появившаяся капиллярно-гравитационная (КГК). Согласно АГК, основными факторами, определяющими изменчивость коэффициента нефтенасыщенности $k_{\text {нн }}$ вверх по разрезу, является коэффициент открытой пористости $\left(k_{\Pi}\right)$ и высота над уровнем свобод-

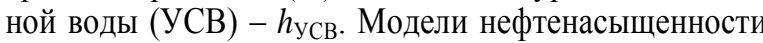
$\left(\mathrm{K}_{\text {нн }}\right)$ сложнопостроенных залежей, созданных на основе АГК, зачастую дают настолько упрощенное (усредненное) представление о геологическом строении, что делают невозможным их использование для решения практических задач (уточним, что $k_{\text {нн }}$ означает коэффициент нефтенасыщенности, а $\mathrm{K}_{\text {нн }}$ - трехмерную модель коэффициента нефтенасыщенности). Низкие прогнозные свойства моделей, созданных на основе антиклинально-гравитационной концепции нефтегазонакопления, послужили основанием для поисков причин этого обстоятельства. Изучение месторождений с низкими значениями ФЕС, а также с ФЕС со значимыми градиентами показало, что изменчивость в них $k_{\text {нн }}$ не согласуется с закономерностями АГК, так как она не учитывает влияние капиллярных сил $\left(P_{\text {к }}\right)$, коэффициента проницаемости $\left(\mathrm{K}_{\text {пр }}\right)$, литологических характеристик (гидрофильность, гидрофобность), влияющих значимо на фильтрацию УВ в резервуаре [6].

Создание адекватной 3D модели нефтенасыщенности невозможно без четкого понимания основных физических и геологических закономерностей изменения этого параметра. В первую очередь следует рассмотреть эти свойства с позиции геометрии залежи, то есть наличия зон, в которых коэффициент $k_{\text {нн }}$ характеризуется отличительными особенностями. В плане выделяют две зоны: зону ЧНЗ (чисто нефтяную) и ВНЗ (водонефтяную), а также границы тектонических и литологических ограничений (выклинивания и замещения), в которых свойства $k_{\text {нн }}$ к настоящему времени достаточно хорошо изучены.

Заметно сложнее $k_{\text {нн }}$ изменяется по разрезу. Причем здесь пока нет единого мнения. Множество точек зрения на эту проблему в грубом приближении можно разделить на два класса (видов моделей).

Согласно первому подходу, в разрезе модели выделяют три области: нижняя - зона остаточной нефтенасыщенности, выше переходная водонефтяная зона (ПВНЗ) и зона предельного нефтенасыщения в кровельной части залежи [8]. Особенности строения этих зон будут проанализированы позже, а пока определимся с границами этих зон. При решении за- дач обоснования проектов разработки и управления разработкой считают, что снизу залежь ограничена поверхностью, получившей название уровня свободной воды (УСВ).

Уровень свободной воды - это поверхность, на которой $k_{\mathrm{Hн}}=0$ и $P_{\mathrm{K}}=0$, а для коэффициента водонасыщенности $\left(k_{\mathrm{B}}\right)$ выполняется равенство: $k_{\mathrm{B}}=1[8,10,11,6]$. Некоторые исследователи в качестве нижней границы рассматривают поверхность $\left(\mathrm{BHK}_{1}\right)$, ниже которой нефть хоть и присутствует, но является неподвижной. Граничное значение $k_{\mathrm{B}}$ на этой поверхности обозначим $k_{\mathrm{B}}^{* *}$. Область, в которой $0<k_{\mathrm{B}}<k_{\mathrm{B}}^{* * *}$, получила название остаточной нефтенасыщенности. Эта область характеризуется низким значением $k_{\text {нн }}$ (остаточная нефтенасыщенность $k_{\text {но }}$ ), при котором фильтрация нефти отсутствует, то есть $k_{\text {нн }}=k_{\text {но }}$, а $k_{\text {в }}$ близок к 1 .

Есть два подхода к выбору верхней границы ПВНЗ. В одном подходе верхней границей является водонефтяной контакт (ВНК, будет рассмотрен далее), в другом -граница, выше которой отсутствует фильтрация воды. Постоянное значение $k_{\text {в }}$ на этой границе обозначим $k_{\mathrm{B}}^{*}$.

В другом, менее распространенном и более детальном, подходе выше УСВ выделяют четыре области. Зона ограничена снизу УСВ, на которой, как сказано выше, $k_{\mathrm{B}}=100 \%$, а сверху - поверхностью, на которой $k_{\mathrm{B}}=k_{\mathrm{B}}^{* *}, k_{\mathrm{B}}^{* *}-$ критическое значение, при котором нефть становится неподвижной Выше по разрезу выделяют область, в которой $k_{\mathrm{B}}$ изменяется от $k_{\mathrm{B}}{ }^{*}$ до $k_{\mathrm{B}}^{\text {гр }}$, в этой области нефть подвижна, но значения $k_{\mathrm{нн}}$ настолько малы, что при вскрытии добывается преимущественно вода. Следующая область характеризуется неравенством $k_{\mathrm{B}}^{\text {Гр }}<k_{\mathrm{B}}<k_{\mathrm{B}}{ }^{*}$. В этом подходе именно эту область называют ПВНЗ. В кровельной части, как и в выше рассмотренной модели, расположена зона предельного нефтенасыщения. Этот подход является частично умозрительным, так как нет методов, позволяющих оценить $k_{\mathrm{B}}^{\text {гр }}$. По этой причине он не используется в трехмерных моделях начальной нефтенасыщенности.

Отметим, что содержание статьи базируется на первом подходе, причем ПВНЗ снизу ограничена УСВ, а сверху - поверхностью, на которой $k_{\mathrm{B}}=k_{\mathrm{B}}{ }^{*}$, то есть поверхностью, являющейся нижней границей зоны предельной нефтенасыщенности.

Значения коэффициента $k_{\text {нн }}$ обусловлены большим числом факторов, причем значимость их сильно зависит от целого ряда геологических, физических, литологических характеристик пород-коллекторов.

Проблема изучения переходных зон и учета их в трехмерном геологическом моделировании особенно актуальна для гидрофильных пород-коллекторов с невысокими ФЕС или высокой их анизотропией. Как показано в ряде исследований, в этих условиях толщина ПВНЗ может достигать нескольких десятков метров (рис. 1) [3, 7, 12]. В однородных высокопроницаемых и в гидрофобных породах-коллекторах ПВНЗ незначительна по толщине, поэтому учет ее строения в алгоритме геолого-гидродинамического моделирования практически не повышает прогнозные показатели модели [6]. 


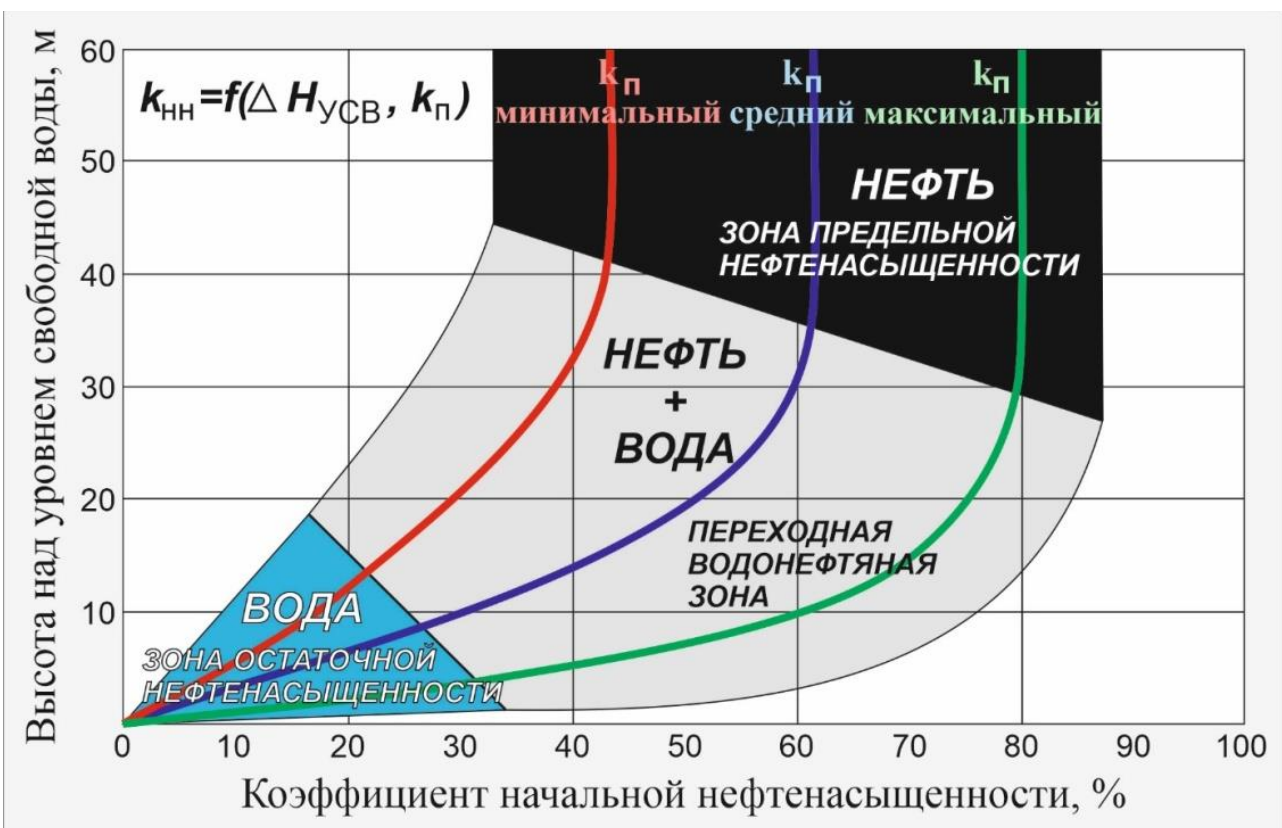

Pис. 1. Схема нефтяной залежи в разрезе согласно капиллярно-гравитационной концепции нефтегазонакопления [6]

Fig. 1. Diagram of an oil deposit in the section according to the capillary-gravity concept of oil and gas accumulation [6]

Как уже было сказано, при создании 3D модели $\mathrm{K}_{\text {нн }}$ важно обосновать выбор нижней границы области моделирования. Ее выбор в значительной степени предопределен целью создаваемой модели. Методы гидродинамического моделирования требуют вычисления значений $k_{\text {нн }}$ от УСВ до кровли пород-коллекторов. В ПВНЗ есть еще одна важная поверхность - ВНК. Наиболее часто под ВНК понимают условную поверхность, разделяющую нефтенасыщенную и водонасыщенную части залежи. Согласно [5]: «ВНК - граничная поверхность в переходной зоне нефтяной залежи, ниже которой фазовая проницаемость для нефти равна нулю, то есть выше которой из пласта получают промышленный приток нефти с водой». Понятие «промышленный приток нефти» не является формализованным по причине существенной зависимости его от целого ряда геологических и экономических факторов, следовательно, и понятие «водонефтяной контакт» тоже не формализованное. В природе нет и не может быть четкой границы, разделяющей области, характеризующиеся $k_{\mathrm{H}}=1$ и $k_{\mathrm{B}}=1$ [6]. Обобщая изложенное о понятии ВНК, можно сказать лишь следующее: ВНК «находится в зоне, расположенной ниже однофазного притока нефти и выше однофазного притока воды» [6]. Методы обоснования ВНК по материалам ГИС приведены в работе [8].

Аналогично понимают газонефтяной и газоводяной контакты. Модели К счета запасов, почти всегда ограничены снизу поверхностью ВНК. Поверхность ВНК может быть горизонтальной, наклонной или выпукло-вогнутой, например, у залежей, у которых в купольной части ведется разработка.

Изучению строения нефтяных залежей с учетом наличия ПВНЗ посвящено большое число исследований: С.И. Билибина, Ю.Я. Большакова, П.А. Боронина, А.Ф. Гималтдинова, Л.Н. Дорогиницкой, Т.Ф. Дьяконовой, К.Е. Закревского, А.Н. Михайлова,
С.Д. Пирсона, В.И. Петерсилье, Ф.3. Хафизова, А.М. Дубины, Т.Г. Исакова, Е.А. Юканова, И.С. Закирова, М.А. Грищенко и другие $[1,3,4,6-8,10,12,13]$. Учет особенностей геологического строения ПВНЗ позволяет повысить адекватность геологических моделей, а значит, и точность решения на их основе ряда важнейших задач: подсчета запасов, составления проектов разработки и обоснования геолого-технических мероприятий с целью повышения нефтеизвлечения.

Нефтяные залежи Западной Сибири большей частью сложены терригенными полимиктовыми породами-коллекторами с существенной неоднородностью по литологическому составу и по проницаемости, как по разрезу, так и по латерали. Толщина ПВНЗ таких залежей значимо изменяется и может достигать нескольких метров.

$B$ зоне предельного нефтенасыщения коэффициент $k_{\text {нн }}$ достигает наибольших значений, а $k_{\mathrm{B}}=k_{\mathrm{B}}{ }^{*}$. В этой зоне имеет место равенство:

$$
k_{\text {нн }}=1-k_{\mathrm{BO}} .
$$

ОФП (относительные фазовые проницаемости) по нефти $\left(k_{\text {пр. }}\right.$. $)$ в этой зоне наибольшая, для большинства месторождений 3 С она близка к единице, по воде $\left(k_{\text {пр. }}{ }^{\text {․ }}\right)$ - равна нулю. Забегая вперед, отметим, что в этой зоне почти никогда не наблюдается зависимости

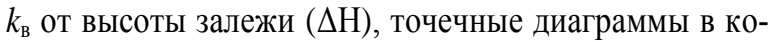
ординатах $\left(k_{\mathrm{B}}, \Delta H\right)$ характеризуются низкими значениями коэффициента детерминации, в этой зоне коэффициент остаточной водонасыщенности зависит только от пористости.

Общие закономерности изменения ОФП в зависимости от высоты над УСВ и характера насыщения показаны на рис. 2 [14]. Точка пересечения этих графиков $k_{\text {в. }}^{\text {гр }}$, как правило, изменятся в интервале 0,5-0,6 д. ед. Для гидрофобных пород-коллекторов она смещена влево, для гидрофильных - вправо. 


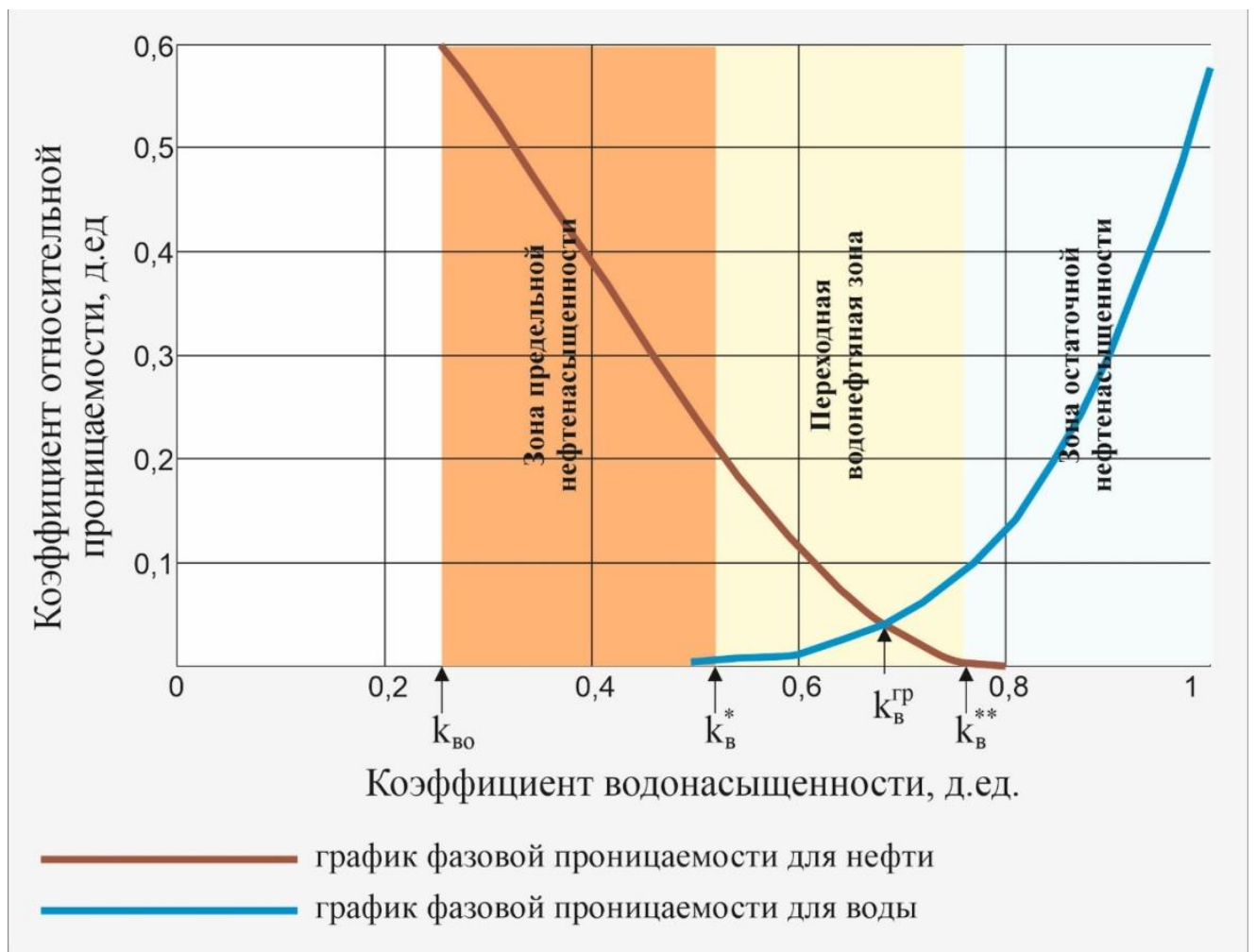

Рис. 2. Общие закономерности изменения относительных фазовых проницаемостей по зонам с различным характером насыщения

Fig. 2. General patterns of changes in relative phase permeabilities in zones with different saturation patterns

ПВНЗ - зона двухфазной фильтрации флюидов, в которой ОФП по нефти и воде меньше единицы: $k_{\text {пр }}{ }^{\text {"}}<1$ и $k_{\text {пр. }}{ }^{\text {в }}<1$ (рис. 2). Коэффициент водонасыщенности в ПВНЗ изменяется в пределах: $k_{\mathrm{B}}{ }^{* *}>k_{\mathrm{B}}>k_{\mathrm{B}}{ }^{*}$, где $k_{\mathrm{B}}^{* *}$ - граничное значение $\mathrm{k}_{\mathrm{B}}$ на нижней границе переходной зоны, $k_{\mathrm{B}}{ }^{*}$ - граничное значение $k_{\mathrm{B}}$ на верхней границе ПВНЗ (рис. 2).

Зона остаточной нефтенасыщенности характеризуется значениями $k_{\mathrm{B}}>k_{\mathrm{B}}^{* *}$. Относительная фазовая проницаемость по воде $\left(k_{\text {пр. }}\right.$. $)$ в этой зоне наибольшая, для большинства месторождений ЗС она близка к единице, а фазовая проницаемость $k_{\text {пр }}{ }^{\text {}}$ практически равна нулю. Другими словами, зона остаточного нефтенасыщения - зона однофазного течения (воды), нефтяная фаза в ней неподвижна.

В настоящее время в нефтяной геологии нет единого понимания ПВНЗ. Рядом авторов она понимается как область между УСВ и ВНК. Другими авторами, в том числе авторами статьи, ПВНЗ трактуется как объем нефтенасыщенного пласта, ограниченный снизу УСВ, на которой водонасыщенность $\left(k_{\mathrm{B}}\right)$ составляет $100 \%$, до поверхности, являющейся подошвой 30ны предельной нефтенасыщенности, в которой $k_{\text {нн }}$ и

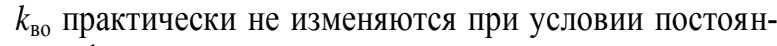
ства фильтрационно-емкостных свойств.

Ввиду указанной высокой значимости для решения задач нефтегазопромысловой геологии трехмерных моделей нефтенасыщения, с одной стороны, и объективных трудностей создания адекватных моделей $\mathrm{K}_{\text {нн }}$, с другой, имеется большое число работ, посвященных этой проблеме. Решение проблемы идет в двух направлениях. В работах одного направления обосновываются новые виды привлекаемой информации (априорной и косвенной), в других совершенствуются алгоритмы интерполяции и аппроксимации. Существенный вклад в развитие алгоритмической базы создания адекватных $3 \mathrm{D}$ моделей $\mathrm{K}_{\text {нн }}$ внесли отечественные ученые: В.А. Бадьянов, С.И. Билибин, Ю.Я. Большаков, А.М. Волков, А.Ф. Гималтдинова, М.А. Грищенко, И.С. Гутман, Е. Ю. Большакова, А.А. Забоева, К.Е. Закревский, А.К. Кашик, Я.В. Кузнецова, Е.В. Ковалевский, А.В. Юрьев и др. [2-6, 12, 14-16], и иностранные - J. Jennings, S. Buckley, M. Leverett, A. Rassas, Xiang Li и др. [10, 17-25].

Моделирование нефтенасыщенности, как и моделирование любых других параметров, основано, прежде всего, на эмпирических данных. Моделируют не сам коэффициент начальной нефтенасыщенности, a $k_{\mathrm{B}}$. Обусловлено это тем, что значения $k_{\mathrm{B}}$ точнее определяются по керну. Переход к 3D модели начальной нефтенасыщенности проводят по формуле, вытекающей из (1)

$$
\mathrm{K}_{\mathrm{HH}}=1-\mathrm{K}_{\mathrm{B}} \text {. }
$$

\section{Анализ качества данных}

Погрешности геологических измерений обусловлены большим количеством субъективных и объективных факторов. Их разделяют на систематические, случайные и грубые (промахи) погрешности. Из этого следует, что необходим анализ значений выборок для обоснования того, какая ситуация имеет место. В зависимости от вида погрешностей проводится даль- 
нейший анализ данных. Например, если в результате анализа показано, что отклонение является следствием ошибки замера, то можно исключить замер из выборки или использовать его с меньшим весовым коэффициентом.

Эмпирические оценки $k_{\text {во }}$ и $k_{\text {но }}$ находятся по керно-

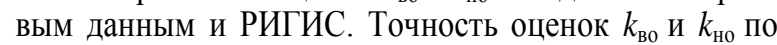
данным керна зависит от целого ряда факторов: характера насыщения интервала разреза, технологии извлечения образцов керна, состава и плотности буровых растворов и так далее. Наиболее точно $k_{\text {во оце- }}$ нивается по образцам керна из зоны предельного нефтенасыщения на герметизированных образцах сразу после извлечения из скважин, пробуренных на безводных буровых растворах. В зоне двухфазной

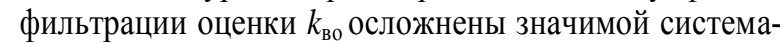
тической погрешностью, так как часть свободной воды вытеснена фильтратом безводного бурового раствора. При использовании буровых растворов на водной основе более точно определяются значения $k_{\text {но }}$.

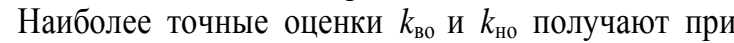
бурении на основе нефильтрующейся промывочной жидкости и равновесии. Но в настоящее время в России такое бурение практически не производится.

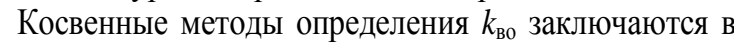
моделировании процесса формирования углеводородной залежи с помощью центрифугирования или капиллярометрии [13]. При определении коэффициента нефтенасыщенности $k_{\text {нн }}$ по данным РИГИС $k_{\text {нн }}^{\text {гис }}$ основными методами являются электрическое сопротивление и/или электромагнитный каротаж. Метод работает только при наличии информации об удельном электрическом сопротивлении пласта $\left(p_{\text {п }}\right)$ и пластовой воды $\left(p_{\text {в }}\right)$ и петрофизических связей типа «керн-керн».

Точность определения $k_{\text {нн }}$ зависит и от строения разреза, в частности, от толщины пропластков породколлекторов. Если в разрезе в непосредственной бли- зости от породы-коллектора присутствуют плотные породы, то значения каротажной диаграммы осложнены дополнительными помехами, завышающими значения сопротивлений на стыке с изучаемым пропластком. Влияние зашумления сопротивления особенно значимо при наличии пропластков породколлекторов толщиной менее 0,8 м, следовательно, значения $k_{\text {нн }}^{\text {гис }}$ таких пропластков в расчетах лучше не использовать.

Кроме того, необходимо проконтролировать нали-

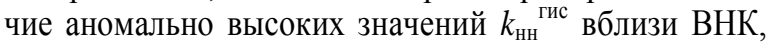
что также может быть связано с высокой погрешностью диаграмм ГИС, обусловленной двухфазной насыщенностью этой зоны [14].

Обязательным этапом при формировании базы данных для решения задачи является анализ качества всех используемых данных. При выявлении систематических погрешностей следует оценить среднее значение погрешности и сделать корректировку данных.

Данные, используемые для построения модели насыщения, прежде всего, необходимо проанализировать на согласованность значений $k_{\mathrm{B}}$, определенных по образцам керна и по данным ГИС: $k_{\mathrm{B}}{ }^{\text {керн }}$ и $k_{\mathrm{B}}{ }^{\text {гис }}$ соответственно. Точки на диаграмме, построенной по этим данным, при приблизительно одинаковой их точности располагаются вдоль биссектрисы первого квадранта. Смещение прямой линии, аппроксимирующей точки $\left(k_{\mathrm{B}}{ }^{\text {керн }}, k_{\mathrm{B}}^{\text {гис }}\right)$ от биссектрисы, говорит о наличии систематических погрешностей, скорее всего в значениях $\mathrm{K}_{\mathrm{B}}^{\text {гис }}$. Величина смещения указанных линий и дает оценку систематической погрешности.

Согласованность данных $k_{\mathrm{B}}^{\text {гис }}$ и $k_{\mathrm{B}}^{\text {керн }}$ можно провести еще другим способом. На точечную диаграмму с оценками $k_{\text {п }}$ и $k_{\mathrm{B}}^{\text {гис }}$ по всем скважинам продуктивной и водонасыщенной частей разреза наносят зависимости $k_{\mathrm{Bo}}\left(k_{\text {п }}\right)$ и $k_{\mathrm{B}} *\left(k_{\text {пा }}\right)$ (рис. 3 ).

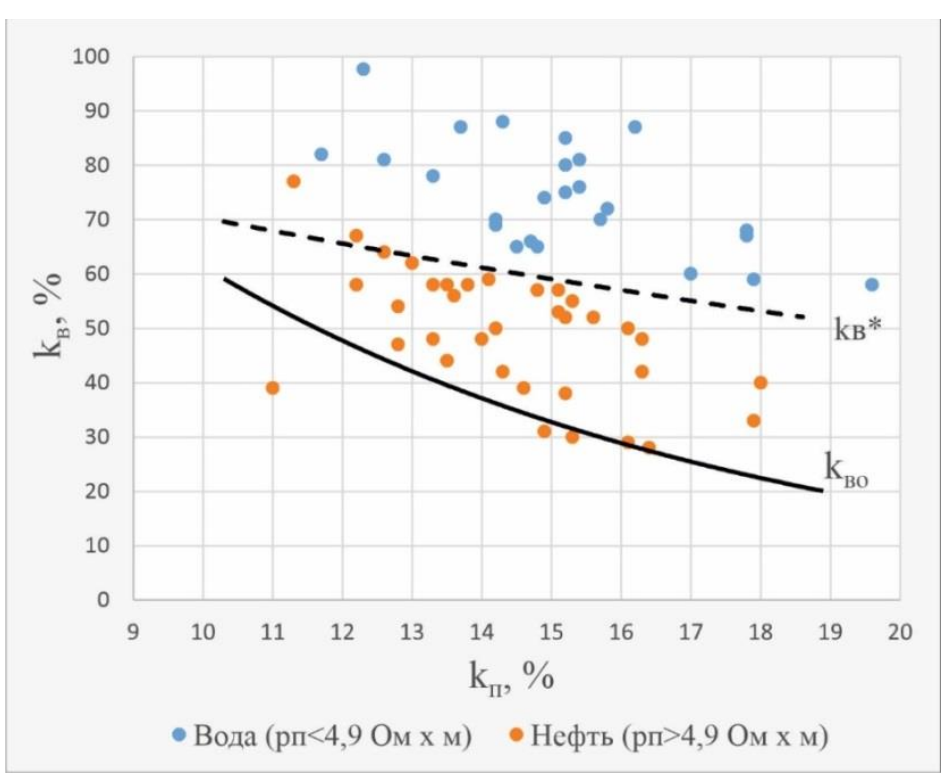

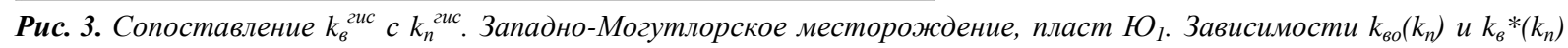
построены по керновым данным [13]

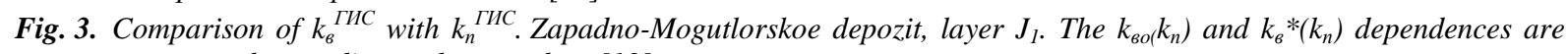
constructed according to the core data [13] 
Если основной массив точек, соответствующий породам-коллекторам с однофазной фильтрацией нефти (зона предельного нефтенасыщения), лежит в области $k_{\mathrm{B}} *\left(k_{\text {п }}\right)>k_{\mathrm{B}}>k_{\mathrm{Bo}}\left(k_{\text {П }}\right)$, то оценки коэффициента нефтенасыщенности по РИГИС являются достоверными и подтвержденными керновыми данными [13].

\section{Обзор методов моделирования нефтенасыщенности}

Согласно исходным данным, используемым при построении $3 \mathrm{D}$ модели $\mathrm{K}_{\mathrm{Hн}}$, все существующие в настоящее время методы делятся на две группы. Первая группа основана на использовании только результатов интерпретации ГИС - коэффициентов пористости и нефтенасыщенности в явном виде или в виде зависимостей, описывающих их совместную изменчивость. Вторая предполагает построение модели насыщенности по петрофизическим зависимостям, полученным по результатам лабораторных исследований керна. Существует ряд методов, основанных на данных РИГИС и керна. Ниже представлен обзор методов создания моделей $\mathrm{K}_{\text {нн }}$ в порядке увеличения сложности, видов и объема исходной геологогеофизической и геолого-промысловой информации.

1. Задание $\mathrm{K}_{\mathrm{Hн}}=$ const для всех ячеек породколлекторов в области моделируемого объема. Методика практически не используется ввиду того, что она не позволяет изучать никакие неоднородности. Но на ранних стадиях разведки при очень малых объемах эмпирических данных, особенно керновых, нет другого варианта.

2. Дискретная модель, заданная набором констант для каждой из обоснованных зон, например, зоны залежей (ЧНЗ, ВНЗ), фаций или литотипов. Область использования этого подхода аналогична предыдущему.

3. Горизонтальная интерполяция значений $\mathrm{k}_{\text {нн }}$ гис (коэффициент нефтенасыщенности, вычисленный по ГИС) - методика также используется редко, поскольку не учитывает зависимость значений коэффициента $\mathrm{k}_{\text {нн }}$ от ФЕС резервуара. Область использования аналогична предыдущим.

4. Стратиграфическая интерполяция значений $k_{\mathrm{Hн}}$ гис дает результаты удовлетворительной точности только в случаях практически неизменяющихся значений $k_{\text {нн }}$ по разрезу пласта. С позиции КГК такие случаи наблюдаются в резервуарах, в которых ПВНЗ практически отсутствует.

5. Интерполяция значений $k_{\text {нн }}^{\text {гис }}$ на основе зависимости:

$$
k_{\mathrm{HH}}=f\left(\Delta H_{\mathrm{BHK}(\mathrm{yCB})}\right) \text {, }
$$

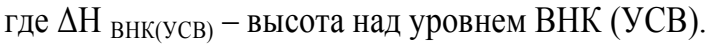

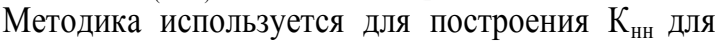
залежей с выдержанными ПВНЗ. Так как залежей такого строения в Западной Сибири крайне мало, то и методика используется также нечасто.

6. Расчет значений $k_{\text {нн }}$ на основе формулы (2). В случае значимых невязок значений $k_{\text {нн }}^{\text {гис }}$ и значений модели $K_{\text {нн }}$, созданной по зависимости (2), выполняется стратиграфическая интерполяция значений $k_{\text {нн }}^{\text {ГИС }}$ с использованием модели $\mathrm{K}_{\text {нн }}$ как трендовой.
Этот подход используется, когда качество регрессионной зависимости (2) характеризуется достаточно высокими значениями коэффициентов корреляции и/или детерминации и не удается выявить более тесные зависимости от других геологических параметров.

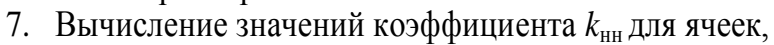
сложенных породами-коллекторами, по зависимости:

$$
k_{\mathrm{HH}}=f\left(k_{\mathrm{\Pi}}\right) \text {. }
$$

Методика используется в случаях отсутствия зависимости (2), это, как правило, залежи предельной нефтенасыщенности.

8. Построение модели $\mathrm{K}_{\text {нн }}$ на основе двумерной зависимости:

$$
k_{\mathrm{H}}=f\left(\Delta H_{\mathrm{BH \kappa}(\mathrm{yCB})}, k_{\mathrm{\Pi}}\right) .
$$

Этот подход, как правило, дает адекватное описание ПВНЗ. Он используется для залежей неоднородного строения, в которых зона предельного нефтенасыщения незначительных размеров. В случае невыдержанности пород-коллекторов значения отметок ВНК значимо варьируют по латерали. В силу этого более адекватной получаются модели $\mathrm{K}_{\text {нн }}$ при использовании зависимости (4) от УCB.

9. Расчет значений $k_{\text {нн }}$ по зависимости (4) с последующей стратиграфической интерполяцией значений $k_{\text {нн }}^{\text {ГИС }}$, которая выполняется в случае неудовлетворительных результатов сопоставления $k_{\text {нн }}^{\text {ГИС }}$ и значений трехмерной модели $\mathrm{K}_{\mathrm{Hн}}$, созданной на основе зависимости (4). Авторы указывают, что эта методика позволяет смоделировать строение переходной зоны в пластах, характеризующихся существенной анизотропией ФЕС $[4,8,14]$.

10. Интерполяция значений $\mathrm{k}_{\text {нн }}$ с использованием четырехмерной зависимости $k_{\text {нн }}=f\left(k_{\text {п }}, k_{\text {пр }}, P_{\text {к }}, \Delta H\right)$. Она применима для залежей со значимыми толщинами ПВНЗ. Зависимости ищутся в классах функций Бакли-Леверетта, Брукс-Кори, Томира, Скелт-Харрисона, Лямбда, Тиксье.

Проанализируем более детально ограничения приведенных методов. Первые три метода, из представленных, не учитывающие физические аспекты процесса нефтенасыщения (даже АГК), применяются на стадиях ранней разведки, в условиях недостатка геолого-геофизической информации, в первую очередь исследований керна.

Остальные методы практически равнозначны с точки зрения применения физических основ, при условии их соответствия критериям применимости, а именно приуроченности объекта моделирования к той или иной зоне насыщения. Как правило, в этом случае выбор стоит между моделью переходной зоны и моделью предельного насыщения и может быть сделан только по результатам анализа представительной выборки результатов испытания скважин. Методы под номерами 4-10 требуют данных РИГИС и керновых данных. Очевидно, что чем больше параметров включено в проектную модель, тем больше 
данных необходимо для получения их оценок с приемлемой точностью.

Достаточность и качество исходных данных в этом случае можно оценить путем сопоставления между собой результатов моделирования, полученных с применением разных методик, с результатами испытания и работы скважин. В условиях представительности исходных данных должна наблюдаться хорошая сходимость, в случае если ее нет, необходимо выявить причины расхождения. Среди них могут быть:

1) неопределённость в значениях минерализации пластовой воды, что приводит к существенной погрешности определения значений $k_{\text {нн }}$ Гис;

2) вторичные изменения горных пород, слагающих объект исследования, которые могут привести к искажениям значений УЭС пластового флюида, и, как результат, - к погрешностям при определении $k_{\text {нН }}^{\text {ГИС }}$

3) непредставительность выборки керновых данных, приводящая к тому, что интервал изменения ФЕС, определенных по результатам исследования керна, существенно меньше, чем по данным РИГИС. В этом случае экстраполяционные значения, определенные по зависимостям «КЕРН-ГИС», осложнены существенной погрешностью, особенно в областях минимальных и максимальных значений ФЕС;

4) неопределенность положения УСВ оказывает существенное влияние на точность коэффициента нефтенасыщенности при его расчете по зависимости от капиллярного давления. Как правило, этот параметр подбирается итерационно;

5) некондиционные испытания скважин

Все вышеперечисленные факторы приводят к высокой неопределенности при прогнозе значений коэффициента нефтенасыщенности в межскважинном пространстве.

Как показано во многих работах, на изменчивость $k_{\text {нн }}$ для многих месторождений Западно-Сибирского нефтегазоносного комплекса с позиции капиллярногравитационной концепции нефтегазонакопления существенное влияние оказывают следующие факторы: пористость, проницаемость, капиллярные силы и высота над УСВ. Вычисление аппроксимирующей функции от четырех переменных вида:

$$
k_{\text {нн }}=f\left(\mathrm{~K}_{\text {п }}, \mathrm{K}_{\text {пр }}, P_{\mathrm{\kappa}}, \Delta H\right)
$$

связано с рядом вычислительных и информационных трудностей объективного характера, поэтому в практике геологического моделирования напрямую не применяется. Что касается информационных причин, они обусловлены отсутствием выборок нужного объема, а также их непредставительностью. Вычислительные сложности построения аппроксимирующей функции от четырех переменных, характеризующейся хотя бы средними значениями коэффициента детерминации $\left(\mathrm{R}^{2}\right)$, связаны с отсутствием простых и достаточно быстрых алгоритмов решения такой задачи. Задачи такого рода решаются, как правило, методом полного перебора. Но, что еще важнее, методы аппроксимации требуют задания класса функции, из которого ищется аппроксимирующая зависимость, а для функции вида (5) они неизвестны.

В настоящее время по результатам анализа экспериментальных данных предложены семь классов функций. Наиболее широко пока используется Ј-функция Бакли-Леверетта [23, 24]. По мнению К.Е. Закревского и А.Ф. Гималтдиновой эффективный метод прогноза насыщенности в залежах, исходя из важной роли капиллярных сил в установлении КГР и движении пластовых жидкостей в пористых средах, основан на использовании ряда других зависимостей: Брукса-Кори [25, 26], Томира, Лямбда, и СкелтХаррисона. Ниже приведены некоторые из этих функций, имеющие в настоящее время наиболее широкое распространение.

Ј-функция Бакли-Леверетта (1941) обобщает значения капиллярного давления по пробам с различными значениями пористости и проницаемости:

$$
J=\frac{3,183 P_{\mathrm{k}} \sqrt{\frac{K_{\text {пр }}}{K_{\text {п }}}}}{\gamma \cos (\theta)},
$$

где $J$ - функция Бакли-Леверетта, д. ед.; $P_{\text {к }}$ - капиллярное давление, $10^{5}$ Па; $k_{\text {пр }}$ - коэффициент проницаемости, $n \cdot 10^{-3}$ мкм $^{2} ; k_{\text {п }}-$ коэффициент пористости, д. ед.; $\gamma$ - поверхностное натяжение на поверхности уг-

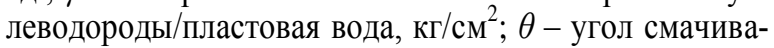
емости, град.

По вычисленным значениям функции (6) и по экспериментальным данным для каждой залежи находят одномерную регрессионную зависимость вида (3): $k_{\mathrm{B}}(J)$.

Несмотря на широкое распространение и использование $J$-функции Бакли-Леверетта для моделирования ПВНЗ, она имеет ограничения: в условиях изменчивой литологии часто наблюдается значимый разброс графиков $k_{\mathrm{B}}(J)$ вокруг осредняющей линии, следствием чего являются дополнительные существенные погрешности, осложняющие значения $k_{\mathrm{B}}$. Это сужает область использования $J$-функции БаклиЛеверетта. В такой ситуации применяют более сложные, но в то же время более гибкие эмпирические модели, такие как Лямбда, Брукс-Кори и Томира.

Функция Брукс-Кори (1964) имеет вид:

$$
k_{\text {в }}=k_{\text {во }}+\left(1-k_{\text {во }}\right)\left(\frac{P_{\text {кач }}^{\text {нач }}}{P_{\text {к }}}\right)^{\frac{-1}{r}} \text {, }
$$

где $k_{\text {во }}$ - остаточная водонасыщенность (д. ед.) верхняя точка по оси ординат капиллярного графика; $P_{\text {к }}-$ капиллярное давление; $P_{\text {к }}^{\text {нач }}-$ начальное капиллярное давление; $\mathrm{r}$ - радиус кривизны капиллярного графика.

В процессе настройки модели вычисляется ряд графиков вида (7) для каждого образца керна. Каждый график описывается функцией Брукс-Кори со своими значениями параметров $k_{\text {во }}, P_{\text {кач }}^{\text {на }} r$ (радиус кривизны капиллярного графика). Затем производится усреднение полученного набора графиков, чаще 
всего методом наименьших квадратов. Если разброс графиков большой, необходим анализ на выяснение причины этого обстоятельства. Значимый разброс может быть обусловлен двумя основными причинами: во-первых, низкой точностью замеров, во-вторых, высокой изменчивостью пород-коллекторов по параметрам, входящим в формулу (7).

Высота над УСВ по каждому графику вычисляется из выражения:

$$
h=\frac{P_{\mathrm{\kappa}}}{\Delta p g},
$$

где $h$ - высота над УСВ, м; $\Delta p$ - разность плотностей воды и нефти, кг $/ \mathrm{M}^{3} ; g-$ ускорение свободного падения $\left(\approx 10 \mathrm{M} / \mathrm{c}^{2}\right)$.

Функиия Томира имеет вид:

$$
k_{\text {в }}=k_{\text {во }}+\left(1-k_{\text {во }}\right)\left(1-e^{\left(g / \ln \left(\frac{P_{\text {выт }}}{P_{\mathrm{K}}}\right)\right)}\right),
$$

где $P_{\text {выт }}$ - давление вытеснения - это капиллярное давление, возникающее в момент, когда несмачивающий флюид соединяется через самые большие поры породы-коллектора и становится связным (до этого был рассеянным), это давление на уровне ВНК или ГНК.

В настоящее время пока нет строгих ограничений и более или менее обоснованных рекомендаций на использование той или иной капиллярной модели в конкретной геологической ситуации. Поэтому для получения наиболее точной модели следует проводить многовариантные расчеты с целью оценки погрешности каждого из существующих методов и обоснования наиболее точного. Как уже было отмечено ранее, единственный критерий, которым при этом можно руководствоваться, - это сходимость результатов, полученных разными методами. В противном случае, необходим анализ причин неадекватности моделей. Во-первых, это может быть обусловлено недостаточным объемом прямых замеров либо осложненностью их систематическими и/или грубыми помехами. Во-вторых, точность метода можно повысить привлечением дополнительной косвенной информации. Ну, и наконец, создание адекватной модели невозможно без пополнения набора алгоритмов новыми методами, эффективными в условиях уникальности как геологического строения изучаемых объектов, так и имеющихся наборов данных.

Для примера рассмотрим результаты, полученные Н.Н. Боженюк при изучении отложений верхней подсвиты викуловской свиты месторождения, расположенного в северной части Красноленинского нефтегазоносного района [27]. В верхней подсвите выделено два пласта - $\mathrm{BK}_{1}$ и ВК 2 , породы-коллекторы которых по литологическому составу классифицируются как отложения аллювиального генезиса. Породы представлены разнопорядко-ритмичным переслаиванием песчаников, алевролитов и глинистых разностей. По керновым данным выделяется большое число песчано-алевролитовых прослоев небольшой толщины, изменяющейся в диапазоне от 1-2 до 5 см. Доля глинистых и алевритоглинистых разностей довольно большая, она составляет 60-65 \%. Высокая литологическая неоднородность и мелкозернистость породколлекторов обуславливает низкие ФЕС. Даже незначительное увеличение коэффициента глинистости приводит к заметному уменьшению $k_{\text {п }}$ и $k_{\text {пр }}$. По классификации А.А. Ханина пласты $\mathrm{BK}_{1}$ и $\mathrm{BK}_{2}$ сложены в подавляющем большинстве породами-коллекторами IV класса, доля пород-коллекторов III класса составляет менее $5 \%$.

В процессе создания трехмерной модели нефтенасыщенности капиллярные модели находились по следующим функциям:

- Бакли-Леверетта;

- Лямбда;

- Томира;

- Брукса-Кори;

- Скелт-Харрисона.

Расчет УСВ проведен на основе зависимости $k_{\mathrm{B}}\left(P_{\mathrm{K}}\right)$ для пород-коллекторов со всеми приведенными капиллярными моделями при различных значениях проницаемости. Анализ качества аппроксимации $k_{\mathrm{B}}\left(P_{\mathrm{\kappa}}\right)$ показал, что для рассматриваемых породколлекторов более точные оценки УСВ получены по зависимости Томира. Абсолютная погрешность по модели Томира (9) почти на 26 \% меньше погрешности, которую дает функция Бакли-Леверетта. Построение 3D модели $\mathrm{K}_{\text {нн }}$ проведено в два этапа. Вначале по капиллярной модели Томира с учетом $3 \mathrm{D}$ моделей пористости, проницаемости и $\mathrm{K}_{\mathrm{B}}$ вычислена трендовая 3D модель нефтенасыщенности $\mathrm{K}_{\text {нн }}{ }^{\text {тp }}$. На втором шаге по данным РИГИС, оцененным методом «АрчиДахнова», с использованием тренда $\mathrm{K}_{\text {нн }}^{\text {тр }}$ вычислена итоговая 3D модель нефтенасыщенности [27].

В заключение рассмотрим два алгоритма построения 3D моделей нефтенасыщенности.

I. Алгоритм построения 3D модели нефтенасыщенности с использованием классификации породколлекторов по пористости (дискретно-непрерывная модель).

Этот алгоритм основан на приближении двухмерной зависимости вида $k_{\text {нн }}=f\left(k_{\text {пा }}, \Delta H\right)$ рядом одномерных вида $k_{\text {нн }}=f(\Delta H)$. Этот подход позволяет создавать адекватные модели $\mathrm{K}_{\text {нн }}$ для залежей с существенно изменяющимися ФЕС с гидрофильными породамиколлекторами, которые имеют незначительную по размерам зону предельной нефтенасыщенности. Создание двухмерной зависимости приемлемого качества указанного вида часто затруднено по объективным причинам: недостаточный объем выборки (особенно при значимых вариациях параметров $k_{\text {нн }}$ и $\left.k_{\text {п }}\right)$ и невозможность обосновать класс функций, в котором методами аппроксимации находится эта зависимость. Один из наиболее перспективных выходов из этой ситуации, по нашему мнению, состоит в создании нескольких более простых зависимостей $k_{\mathrm{Hн}}=f(\Delta H)$ для разных интервалов пористости. Разбиение размаха варьирования $k_{\text {п }}$ на несколько непересекающихся подинтервалов (отрезков) дает возможность работы с одномерными функциями меньшей изменчивости. При работе с одномерными функциями обоснованию 
выбора класса для функции $k_{\text {нн }}=f\left(k_{\text {п }}\right)$ помогают точечные диаграммы. Схема алгоритма имеет вид:

1) создание дискретного параметра характера насыщенности - 3D модели, в которой каждая ячейка выше ВНК имеет значение 1 (нефть), ниже - 0 (вода);

2) анализ изменчивости параметра $k_{\text {п }}$ При большом размахе варьирования следует обосновать необходимость деления его на несколько подинтервалов (классов). Например, при построении модели насыщенности для одного из месторождений ЗСНГБ интервал изменения пористости разбит на три класса (рис. 4): 12,0..14,0; 14,0..15,5; $15,5 \ldots 17,0 \%$.

3) разбиение массива эмпирических значений (скважинных данных) $\mathrm{k}_{\text {п }}$ на подмассивы проводится в соответствии с классификацией, принятой в пункте 2. Цвет точек нефтенасыщенности на диаграмме соответствует классу пористости (рис. 4). Из характера расположения точек видно, что точки разбиваются на три отдельных подмножества, правда, с некоторым перекрытием. Затем методом наименьших квадратов находятся зависимости вида $k_{\text {нн }}=f(\Delta H)$ по исходным скважинным данным для каждого класса. Далее эти уравнения используются как одномерные тренды (косвенная информация).

4) создание модели нефтенасыщенности по регрессионным зависимостям, вычисленным в пункте 3 , выполняется следующим образом: для каждой ячейки $3 \mathrm{D}$ модели $\mathrm{K}_{\text {нн }}$ по модели $\mathrm{K}_{\text {п }}$ находится соответствующее ей значение. По найденному значению $k_{\text {п }}$ определяется класс (в соответствии с классификацией пункта 2), и значение $\mathrm{K}_{\text {нн }}$ вычисляется по соответствующему уравнению. На этом шаге надо обязательно использовать граничные

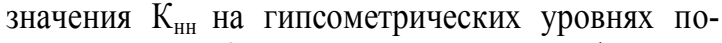
верхности ВНК и зоны предельной нефтенасыщенности. Это позволяет избежать больших погрешностей в зонах экстраполяции.

5) создание итоговой модели $K_{\text {нн }}$. При ее создании кроме прямых замеров в качестве трехмерного тренда следует использовать модель нефтенасыщенности, вычисленную на шаге 4.

6) оценка качества модели насыщенности.

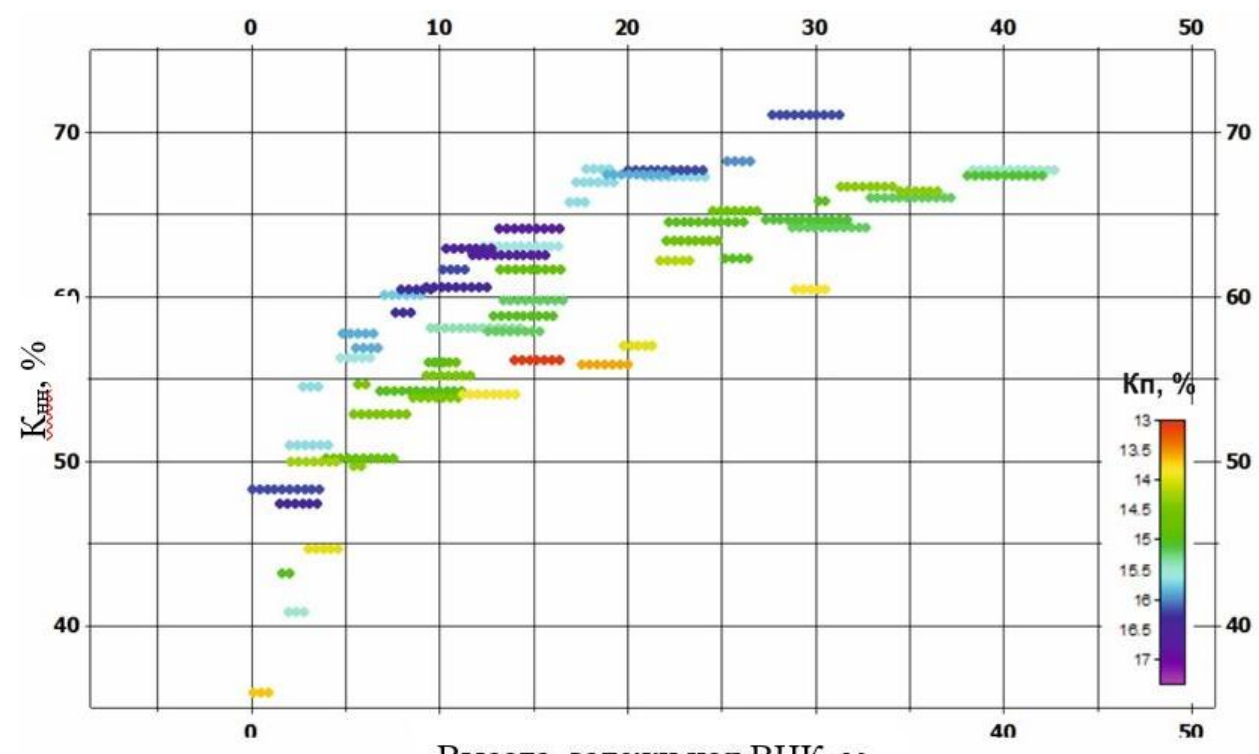

Pис. 4. Эмпирические зависимости $k_{\text {нн }}(\Delta H)$ при различных значениях пористости

Fig. 4. Empirical dependences of $k_{н н}(\Delta H)$ at different porosity values

II. Почти все алгоритмы построения 3D модели $\mathrm{K}_{\mathrm{B}}$ с учетом переходной зоны предполагают горизонтальное строение УСВ. Ниже изложен алгоритм построения $3 D$ модели $K_{\text {во }}$ с учетом переходной зоньл, причем допускающий криволинейную форму УСВ. Алгоритм приведен на примере построения 3D модели нефтенасыщенности для пород-коллекторов пласта $\mathrm{ЮB}_{1}{ }^{1}$ месторождения «А» с использованием значений капиллярного давления. Косвенными данными по этой методике являются $3 \mathrm{D}$ модели $\mathrm{K}_{\text {п }}$ и $\mathrm{K}_{\text {пр }}$, данные

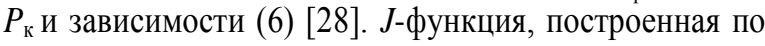
данным шестнадцати проб керна в восьми скважинах, приведена на рис. 5 [1].

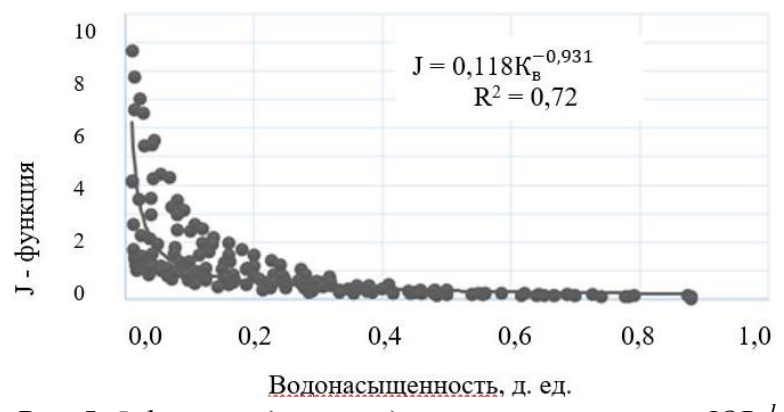

Pис. 5. Ј-функция для пород-коллекторов пласта $Ю_{1}{ }^{1}$ месторождения «A»

Fig. 5. J-function for rocks of the $U V_{1}{ }^{l}$ reservoir of the field «A» 
Терригенные полимиктовые породы-коллекторы пласта ЮВ $_{1}{ }^{1}$ характеризуются высокой литологической неоднородностью и слабой согласованностью изменения значений $k_{\text {п и }} k_{\text {пр. }}$. Высокие значения $k_{\text {гл и }}$

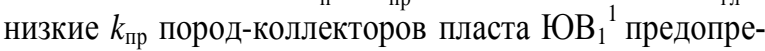
деляют наличие существенной по размерам и достаточно сложной по геологическому строению, как по разрезу, так и по латерали, ПВНЗ $[1,4,12]$. Алгоритм построения модели нефтенасыщенности в приведенном примере с учетом геологического строения ПВНЗ имеет вид [1]:

1) по капиллярометрическим керновым данным находят значения $k_{\text {во и }} P_{\mathrm{K}}$, которые позволяют вычислить значения $J$-функции;

2) подстановкой значения $k_{\mathrm{B}}^{\text {гр }}$ на ВНК в формулу (6) рассчитывается значение $J$-функции, соответствующее уровню ВНК. По выражению для $P_{\text {к из }}$ формулы (6) строится 3D модель параметра $P_{\mathrm{K}}$ от ВНК до УСВ. Положение УСВ соответствует значению $P_{\mathrm{K}}=0$;

3) по формуле (8) рассчитываются расстояния от ВНК до УСВ и строится карта толщин этой зоны;

4) после определения поверхности УСВ (подошвы ПВН3) рассчитывается 3D модель капиллярных

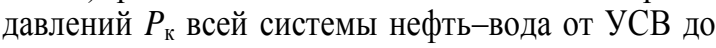
верхней границы залежи;

5) по значениям капиллярного давления $P_{\text {к всей си- }}$ стемы нефть-вода и ФЕС пород-коллекторов рассчитывается значения Ј-функции по формуле (6) для всех ячеек моделируемого пространства;

6) по зависимости, обратной к $J=f\left(K_{\mathrm{B}}\right)$, вычисляются значения трендового куба $\mathrm{K}_{\mathrm{B}}^{\text {тp}}$;

7) итоговая модель $K_{\mathrm{B}}$ залежи пласта $\mathrm{ЮB}_{1}{ }^{1}$ вычислена интерполированием замеренных значений водонасыщенности с использованием двух трендов: 3D модели $\mathrm{K}_{\mathrm{B}}^{\mathrm{Tp}}$ и J-функции Бакли-Леверетта (одномерный тренд).

Затем вычисляется итоговая трехмерная модель нефтенасыщенности по формуле:

$$
\mathrm{K}_{\mathrm{HH}}=1-\mathrm{K}_{\mathrm{B}} \text {. }
$$

Трехмерные модели $\mathrm{K}_{\text {нн }}$ позволяют строить карты толщин ПВЗП и зон предельной нефтенасыщенности.

Карта толщин переходной зоны $\left(h_{\text {пз }}\right)$ залежи пласта $\mathrm{OB}_{1}{ }^{1}$ месторождения «A» характеризуется сложным геометрическим строением, она существенно неоднородна, на ней наблюдается тренд увеличения толщин от контура нефтеносности к зоне глинизации (рис. 6).

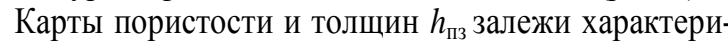
зуются обратной корреляционной зависимостью, что хорошо согласуется с геологическими закономерностями строения залежей с литологическими ограничениями и капиллярно-гравитационной концепцией нефтегазонакопления.

Детальное описание геологического строения залежи, получаемое по методам с учетом ПВНЗ, позволяет более достоверно оценить запасы по выявленным зонам: ПВНЗ и зоне предельной нефтенасыщенности. Это, несомненно, является важной информацией для обоснования стратегии нефтеизвлечения и, следовательно, повышения КИН.

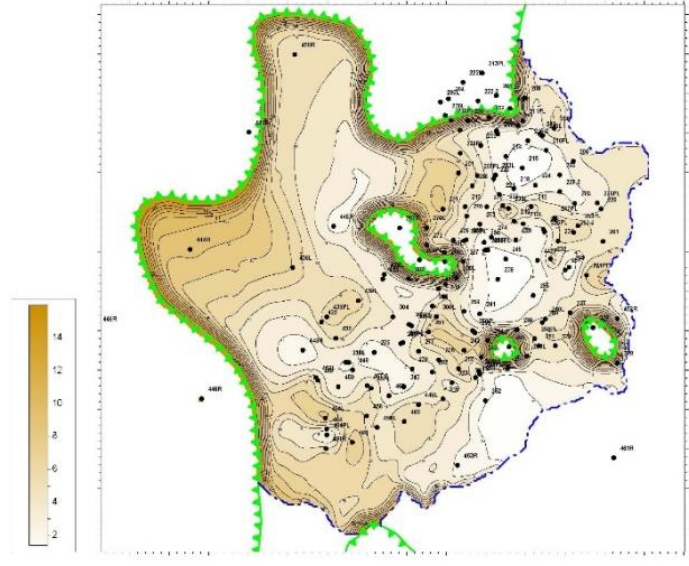

Puc. 6. Карта толщчин переходной водонефтяной зоны залежи пласта ЮВ ${ }_{1}{ }^{l}$ месторождения "А»

Fig. 6. Map of the thickness of the transition water-oil zone of the $U V_{l}^{l}$ formation of the "A» field

В случае наличия в объекте зон с существенно различными ФЕС и смачиваемостью пород-

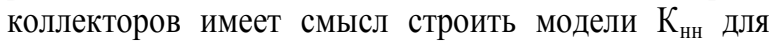
каждой из зон, другими словами, построить ДНМ. Если зоны не связаны ни с литологическими замещениями, ни с гидродинамически непроницаемыми тектоническими нарушениями (в таких случаях моделируемые функции разрываются на границах), параметры ФЕС и капиллярное давление непрерывны. Модель же, построенная по отдельным зонам, как правило, не будет удовлетворять требованию непрерывности. С целью достижения этого условия необходимо создать модель по всему трехмерному геологическому объекту с использованием моделей по отдельным зонам как трендовых.

\section{Методы оценки качества трехмерных моделей}

Оценка качества модели насыщения, как и любого другого этапа создания 3D ГМ, проводится по двум видам проверки - внутренней и внешней. Критерии оценки качества зависят от конечных целей моделирования, которые в грубом приближении можно разделить на три задачи: оценка начальных геологических запасов УВ, контроль и повышение эффективности разработки, проектирование и мониторинг бурения скважин.

Внутренняя проверка ГМ представляет собой анализ согласованности всех возможных составляющих компонент базы исходных данных, а также анализ отклонений модели от этих данных. В зависимости от целей создания ГМ он может включать такие виды анализа:

1) сравнение средневзвешенных значений и оценок дисперсии нефтенасыщенности по скважинным данным и по 3D модели;

2) построение точечной диаграммы значений $k_{\text {нн }}$ по скважинным данным и по 3D модели;

3) сравнение гистограмм частот значений $k_{\text {нн }}^{\text {ГИС }}$ и $3 \mathrm{D}$ модели $\mathrm{K}_{\text {нн }}$;

4) построение карты коэффициента нефтенасыщенности по 3D модели и сравнение ее с картой, вычисленной по значениям $k_{\text {нн }}$ с скважинах. 
В зависимости от выбранной методики моделирования и количества скважинных данных допустимое расхождение по каждому из перечисленных выше критериев может существенно варьировать. Так, например, если реализована модель предельного насыщения, для объекта вскрытого плотной сеткой скважин расхождение по всем четырем критериям не должно превышать $\pm 5 \%$. В случае если реализована модель с переходной зоной на основе данных капиллярометрических исследований керна, а объект моделирования слабо охарактеризован скважинными данными, допустимо варьирование средневзвешенных значений в более широком диапазоне.

Внешняя оценка качества геологической модели основана, во-первых, на анализе согласия построенной модели с информацией, не используемой в вычислительном процессе. В первую очередь внешняя проверка основана на оценке сходимости результатов моделирования, которые в качестве исходных данных используют разные источники геолого-геофизической информации - керн и ГИС. Так, для модели переходной зоны с учетом капиллярометрических исследований керна оценивают сходимость значений $\mathrm{k}_{\text {нн }}$ по модели и по данным РИГИС по формуле Арчи-Дахнова. Оценка проводится по первым трем критериям, описанным во внутренней оценке качества.

Сравнение средневзвешенных значений $k_{\text {нн }}$ по скважинам и по модели корректно проводить только в случае, если моделируемый объект характеризуется существенной выдержанностью по разрезу, средней толщиной пропластков коллектора более 1 м, низким коэффициентом расчлененности. Если объект моделирования удовлетворяет описанным выше критериям, то также проводят сопоставление значений $k_{\text {нн }}$ в интервале отдельных пропластков породколлекторов. В противном случае оценка проводится только путем сопоставления гистограмм частот параметра нефтенасыщенности и их статистических характеристик по скважинным данным и по 3D модели. Если наблюдается существенное расхождение между скважинными данными и моделью, необходимо провести оценку достоверности исходных данных, используемых для расчета $k_{\text {нн }}$ в обоих случаях. Основными источниками неопределенности при оценке $k_{\text {нн }}$ по данным ГИС по формуле Арчи-Дахнова являются величина минерализации пластовой воды и замеренные значения УЭС. При расчете $k_{\text {нн }}$ по данным капиллярометрических исследований керна наименее достоверно определяемым параметром является положение УСВ, однако такие факторы, как методика проведения лабораторных экспериментов и качество выборки образцов керна, также оказывают существенное влияние на конечный результат моделирования. Совокупная оценка качества всех перечисленных факторов позволит выбрать приоритетный под-

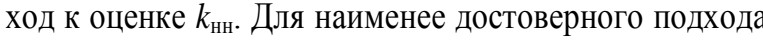
допустимо итерационное варьирование значений параметров, характеризующихся наибольшей неопределенностью, до достижения наилучшей сходимости расчётных значений $k_{\text {нн }}$ по двум методикам. В случае если для обоих подходов в оценке $k_{\text {нн }}$ большинство параметров, участвующих в расчётах, характеризуются примерно одинаковой степенью неопределенности, выбор проводится на основе сравнения с фактическими показателями разработки (четвертый критерий внешней проверки).

Во-вторых, внешняя проверка может быть осуществлена по вновь полученным фактическим данным, например, данным дебитов вновь пробуренных скважин. Несущественные отклонения новых данных от модели указывают на адекватность и хорошие прогностические свойства модели. Наиболее надежные выводы получаются в случае, когда вновь пробуренная скважина располагается на значительном удалении от скважин, по данным которых построена модель. В этом случае модель обладает надежными прогностическими свойствами не только в зоне интерполяции, но, что еще более важно, и в области экстраполяции.

В-третьих, если имеются результаты гидродинамического каротажа (ГДК) высокоточных глубинных манометров, следует сопоставить оценки УСВ по ГДК и по 3D модели. В случае несогласия этих значений предпочтение отдается инструментальным замерам. Трехмерная модель начальной нефтенасыщенности в этом случае нуждается в корректировке.

В-четвертых, для разрабатываемых месторождений модель должна находиться в согласии с технологическими параметрами. Как правило, это соответствие оценивается на этапе адаптации гидродинамической модели.

\section{Заключение}

Рассмотрены методы описания начальной нефтенасыщенности в объеме трехмерного геологического объекта. Моделирование осуществляется как по наблюденным данным, полученным в ходе геологоразведочного процесса, так и по различным видам априорной и косвенной информации.

Намечены перспективы совместного использования геолого-геофизических, гидродинамических данных и результатов капиллярометрических исследований при решении таких задач, как выделение переходных зон и зон предельной нефтенасыщенности, связанных с представляющим интерес геологическими объектами (залежь, резервуар в случае его замещения или выклинивания, отложения клиноформенного комплекса и др.).

Дальнейшее развитие методов моделирования нефтенасыщенности (начальной, текущей) в ближайшее время, по нашему мнению, пойдет в трех направлениях:

- использование более широко методов дискретнонепрерывного моделирования [29];

- разработка новых видов априорной и косвенной информации;

- совершенствование методов интерполяции и аппроксимации [30];

- оценка неопределенности модели.

Как представляется на данном этапе, со временем станет возможным комплексирование методик каж- 
дого из подходов в едином графе обработки, что заметно повысит ооавтоматизацию процесса создания трехмерных моделей и, следовательно, заметно расширит возможности многовариантных расчетов.

Изложенный в работе алгоритм моделирования с классификацией по пористости является, по сути, методом создания ДНМ. Область модели разбивается в этом конкретном примере на три части, далее в каждой из областей используются свои тренды.

Так как в зонах, сформировавшихся в разных фациальных обстановках или являющихся разными литотипами, вполне вероятно, значения нефтенасыщенности изменяются по разным зависимостям от геологических параметров, то и тренды, вычисленные по разным фациям или литотипам, будут более тесные по сравнению с трендом по всей области моделирования, что означает их более высокую информативность.

Что касается второго направления, в настоящее время заметно увеличивается точность инструментальных замеров, и, что еще более важно, растет и число замеряемых физических параметров. Наиболее показательными в этом плане являются методы высокоточной трехмерной сейсморазведки и сейсмическо-

\section{СПИСОК ЛИТЕРАТУРЫ}

1. Антипин Я.О., Белкина В.А. Моделирование нефтенасыщенности залежей с учётом переходной водонефтяной зоны на примере месторождения А // Территория нефтегаз. - 2016. № 5. - С. 22-29.

2. Билибин С.И. Технология создания и сопровождения трехмерных цифровых геологических моделей нефтегазовых месторождений: автореф. дис. ... д-ра техн. наук. - М., 2010. - 45 с.

3. Большаков Ю.Я. Нетрадиционные капиллярно-экранированные залежи нефти и газа в терригенных коллекторах, условия их формирования и возможности поисков: автореф. дис. ... д-ра геол.-минерал. наук. - Новосибирск, 1987. - 32 с.

4. Грищенко М.А. Современные подходы к моделированию нефтенасыщенности сложнопостроенных залежей с целью создания гидродинамических моделей // Геология нефти и га3а. - 2008. - № 5. - С. 75-80.

5. Новые технологии при построении цифровых геологических моделей месторождений углеводородов / А.С. Кашик, С.И. Билибин, Г.Н. Гогоненков, С.А. Кирилов // Технологии ТЭК. - 2003. - № 3. - С. 12-17.

6. Кузнецова Я.В. Моделирование нефтенасыщенности пластов, залегающих под нефтематеринскими породами (на примере верхнеюрских отложений Западной Сибири): дис. ... канд. геол.-минерал. наук. - Тюмень, 2016. - 163 с.

7. Михайлов А.Н. Основные представления о переходных зонах и водяных контактах в неоднородных пластах// Георесурсы. Геоэнергетика. Геополитика. - 2012. - № 1 (5). - С. 150-160.

8. Проблемы обоснования водонефтяного контакта по материалам геофизических исследований скважин при построении детальных геологических моделей / Т.Ф. Дьяконова, С.И. Билибин, А.М. Дубина и др. // Каротажник. - 2004. - № 3-4. C. 83-97.

9. Ахметова 3.Р. Структуризация остаточной нефтенасыщенности для обоснования технологии доизвлечения нефти: автореф. дис. ... канд. техн. наук. - М., 2016. - 24 с.

10. Jennings J.B. Capillary pressure techniques application to exploration and development geology // The American Association of Petroleum Geologist Bulletin. - 1987. - V. 71. P. 1196-1209.

11. Пестов В.В., Москаленко И.В., Александров Б.Л. Определение начальной нефтенасыщенности терригенных коллекторов миоцен-олигоцена Западного Предкавказья на основе капилляриметрических исследований керна // Нефтяное хозяйство. - 2014. - № 11. - С. 28-30. го зондирования. В последние 3-5 лет активно ведутся работы по созданию трехмерных цифровых моделей керна. Это позволит обосновать новые виды косвенной информации (тренды), а также строить тренды с более высокими прогностическими свойствами.

Третье направление развития методов моделирования связано с совершенствованием методов интерполяции и аппроксимации. В настоящее время с нашей точки зрения наиболее перспективными алгоритмами являются методы нейронных сетей и геостатистики.

В связи с уникальностью каждого геологического объекта и используемых наборов данных решение задачи моделирования с достаточной точностью невозможно без широкого круга различных методов, алгоритмов и подходов. Множество рассмотренных в работе геологических ситуаций разнообразно, но оно не охватывает все проблемы моделирования насыщенности в целом. Остался незатронутым целый ряд проблем моделирования важнейшего геологического параметра - коэффициента нефтенасыщенности, который нельзя свести к решению одной из рассмотренных задач. Это не значит, что не существует приближенных методов их решения, но пока они не найдены.

12. Большакова Е.Ю. Моделирование нефтяных и газовых залежей на основе капиллярно-гравитационной концепции нефтегазонакопления с целью повышения эффективности их разведки и разработки (на примере месторождений Западной Сибири): дис. ... канд. геол.-минерал. наук. - Тюмень, 2006. $200 \mathrm{c}$.

13. К вопросу оценки параметров переходной зоны с использованием кривых капиллярного давления: совершенствование методики разведки нефтяных и газовых месторождений / В.И. Петерсилье, Ю.Я. Белов, М.Ф. Веселов и др. // Труды ВНИГНИ. - М.: Недра, 1982. - Вып. 242. - С. 63-70.

14. Закревский К.Е. Геологическое 3D моделирование. - М.: ООО «ИПЦ Маска», 2009. - $376 \mathrm{c.}$

15. Забоева А.А. Разработка методик трехмерного геомоделирования в условиях неоднородности и неравномерности геолого-геофизической информации (на примере месторождений Западной Сибири): дис. ... канд. геол.-минерал. наук. - Тюмень, 2012. - $167 \mathrm{c}$.

16. Юрьев А.В. Совершенствование методов определения фильтрационно-емкостных свойств пород-коллекторов с применением полноразмерного керна (на примере ряда месторождений севера Тимано-Печорской нефтегазоносной провинции): дис. ... канд. техн. наук. - Пермь, 2019. - 122 с.

17. Application of 3D reservoir geological model on Es1 formation, Block Nv32, Shenvsi Oilfield, China / A. Rassas, S. Ren, R. Sun, A. Zafar, S. Moharam, Z. Guan, A. Ahmed, M. Alomaisi // Open Journal of Yangtze Oil and Gas. - 2020. - V. 5. - № 2. - P. 54-72.

18. Xiang Li. Three-dimensional geological modeling methods and applications - a Gold Belt Oilfield // 3rd International Conference on Management, Education, Information and Control (MEICI). Jinan, China, 2015. - P. 3-10.

19. Дойч К.В. Геостатистическое моделирование коллекторов. М.; Ижевск: Институт компьютерных исследований, 2011. $400 \mathrm{c}$.

20. Gao Xingjun. Applied research of NMR movable fluid saturation in development of low permeability oilfield // E3S Web of Conferences Innovative Technologies in Science and Education. 2020. - V 210. - P. 1-7.

21. Kuiqian Ma. Techniques for improving the water-flooding of oil fields during the high water-cut stage // Oil \& Gas Science and Technology - Rev. IFP Energies Nouvelles. - 2019. - V. 74. P. 1-12.

22. An improved method for quantifying liquid saturation using transparent soil / Juan Wang, Wei Liu, Wenwu Chen, Xuebin Ran, 
Yanfang Zhang, Gaochao Lin // Advances in civil engineering. 2019. - V. 1. - P. 1-11.

23. Buckley S.E., Leverett M.C. Mechanism of fluid displacement in sands // Transactions of the American Institute of Mining, Metallurgical and Petroleum Engineers. - 1942. - V. 146. P. 107-116.

24. Leverett M.C. Capillary behavior in porous solids // Transactions of the American Institute of Mining, Metallurgical and Petroleum Engineers. - 1941. - V. 142. - P. 148-152.

25. Li Kewen. Theoretical development of the brooks-corey capillary pressure model from fractal modeling of porous media // Symposium on Improved Oil Recovery. - Tulsa, Oklahoma, 17-21 April, 2004. - P. 3-9.

26. Akhmetov R.T., Kuleshova L.S., Mukhametshin V.V. Application of the Brooks-Corey model in the conditions of lower cretaceous deposits in terrigenous reservoirs of Western Siberia // IOP Conference Series: Materials Science and Engineering. - 2018. V. 560. - P. 4-12.
27. Боженюк Н.Н. Методы адаптации и снижения и неопределенностей при геолого-гидродинамическом моделировании терригенных коллекторов на примере ряда месторождений Западной Сибири: дис.... канд. геол.-минерал. наук. - Тюмень, 2018. $-172 \mathrm{c}$.

28. Elshahawi H., Fathy K., Hiekal S. Capillary pressure and rock wettability effects on wireline formation tester measurements // IEOC 567121999 SPE Annual Technical Conference and Exhibition. - Houston, Texas, 1999. - P. 1-16.

29. Санькова Н.В., Дорошенко А.А., Белкина В.А. Дискретнонепрерывные модели в задаче прогноза флюидодинамических характеристик коллекторов // Наука и ТЭК. 2012. - № 3. - C. 44-47.

30. Tikhomirova E.A., Sagirova L.R., Khaibullina K.Sh. A review on methods of oil saturation modelling using IRAP RMS // IOP Conf. Series: Earth and Environmental Science. - 2019. - V. 378. P. 1-6.

Поступила 25.08.2021 2.

\section{Информация об авторах}

Белкина В.A., кандидат физико-математических наук, доцент кафедры геологии месторождений нефти и газа Института геологии и нефтегазодобычи Тюменского индустриального университета.

Антипин Я.O., соискатель ученой степени кандидата геолого-минералогических наук Института геологии и нефтегазодобычи Тюменского индустриального университета.

Забоева A.A., кандидат геолого-минералогических наук, доцент кафедры геологии месторождений нефти и газа Института геологии и нефтегазодобычи Тюменского индустриального университета. 
UDC 553.98.048-047.58

\title{
BUILDING THREE-DIMENSIONAL MODELS OF OIL SATURATION. MAIN PROBLEMS AND APPROACHES TO THEIR SOLUTION
}

\author{
Valentina A. Belkina ${ }^{1}$, \\ belkinava@tyuiu.ru \\ Yaroslav 0. Antipin', \\ 0000-9015@rambler.ru
}

Alexandra A. Zaboeva ${ }^{1}$, Alexandra.zaboeva@gmail.com

1 Tyumen Industrial University, 38 , Volodarsky street, Tyumen, 625000, Russia.

The relevance of the analysis of methods for constructing three-dimensional models of initial oil saturation is caused by their wide use in solving the most important problems of oil and gas field geology: calculating reserves, designing and managing development, etc. The accuracy of solving these problems directly determines the efficiency of hydrocarbon extraction.

The goal is to analyze the current state of the algorithmic base of three-dimensional modeling of oil saturation, to identify the main problems and the most promising areas of development.

Interpolation methods: deterministic and stochastic. For different geological situation, these methods can be modified by using indirect and apriori information. Possible types and methods of using indirect information for various geological situations.

Results. The main possibilities of improving the accuracy of three-dimensional models of oil saturation are identified. The methods of checking the quality of the initial data and the adequacy of the constructed models are classified. Specific algorithms for creating models for two most promising areas of development of the algorithmic base for three-dimensional oil saturation modeling are presented.

\section{Key words:}

Initial oil saturation, three-dimensional model, transition oil-water zone, modeling methods, indirect information, capillary forces.

\section{REFERENCES}

1. Antipin Ya.O., Belkina V.A. Modeling of oil saturation of deposits taking into account the transition water-oil zone on the example of A field. Territoriya neftegaz, 2016, no. 5, pp. 22-29. In Rus.

2. Bilibin S.I. Tekhnologiva sozdaniya $i$ soprovozhdeniya trexmernykh tsifrovykh geologicheskikh modeley neftegazovykh mestorozhdeniy. Avtoreferat Dis. Dokt. nauk [Technology for creating and maintaining three-dimensional digital geological models of oil and gas fields. Dr. Diss. Abstract]. Moscow, 2010. 45 p

3. Bolshakov Yu.Ya. Netraditsionnye kapillyarno-ekranirovannye zalezhi nefti $i$ gaza $v$ terrigennykh kollektorakh, usloviya ikh formirovaniva i vozmozhnosti poiskov. Avtoreferat Dis. Dokt. nauk [Non-traditional capillary-shielded deposits of oil and gas in sandstone reservoirs, the conditions of their formation and the possibility of seeking. Dr. Diss. Abstract]. Novosibirsk, 1987. 32 p.

4. Grishhenko M.A. Modern approaches to modeling the oil saturation of complex deposits in order to create hydrodynamic models. Geologiya nefti i gaza, 2008, no. 5, pp. 75-80. In Rus.

5. Kashik A. S., Bilibin S. I., Gogonenkov G. N., Kirilov S. A. Novye tekhnologii pri postroenii tsifrovykh geologicheskikh modeley mestorozhdeniy uglevodorodov [New technologies in the construction of digital geological models of hydrocarbon deposits]. Tekhnologii TEK, 2003, no. 3, pp. 12-17.

6. Kuzneczova Ya.V. Modelirovanie neftenasyshchennosti plastov, zalegayushchikh pod neftematerinskimi porodami (na primere verkhneyurskikh otlozheniy Zapadnoy Sibiri). Dis. Kand. nauk [Modeling of oil saturation of the layers lying under the oil source rocks (on the example of the Upper Jurassic deposits of Western Siberia). Cand. Diss.]. Tyumen, 2016. 163 p.

7. Mikhaylov A.N. Basic concepts of transition zones and water contacts in heterogeneous formations. Georesursy. Geoenergetika. Geopolitika, 2012, no. 1 (5), pp. 150-160.In Rus.

8. Dyakonova T.F., Bilibin S.I., Dubina A.M. Problemy obosnovaniya vodoneftyanogo kontakta po materialam geofizicheskikh issledovaniy skvazhin pri postroenii detalnykh geologicheskikh modeley [Problems of substantiation of water-oil contact based on the materials of geophysical studies of wells in the construction of detailed geological models]. Karotazhnik, 2004, no. 3-4, pp. 83-97.
9. Akhmetova Z.R. Strukturizatsiya ostatochnoy neftenasyshchennosti dlya obosnovaniya tekhnologii doizvlecheniya nefti. Avtoreferat Dis. Kand. nauk [Structuring of residual oil saturation to justify the technology of oil recovery. Cand. Diss. Abstract]. Moscow, 2016. $24 \mathrm{p}$.

10. Jennings J.B. Capillary pressure techniques application to exploration and development geology. The American Association of Petroleum Geologist Bulletin, 1987, vol. 71, pp. 1196-1209.

11. Pestov V.V., Moskalenko I.V., Aleksandrov B.L. Determination of the initial oil saturation of terrigenous reservoirs of the MioceneOligocene of the Western Ciscaucasia on the basis of capillarimetric core studies. Neftyanoe khozyaystvo, 2014, no. 11, pp. 28-30. In Rus.

12. Bolshakova E.Yu. Modelirovanie neftyanykh i gazovykh zalezhey na osnove kapillyarno-gravitatsionnoy kontseptsii neftegazonakopleniya s tselyu povysheniva effektivnosti ikh razvedki $i$ razrabotki (na primere mestorozhdeniy Zapadnoy Sibiri). Dis. Kand. nauk [Modeling of oil and gas deposits based on the capillary-gravity concept of oil and gas accumulation in order to increase the efficiency of their exploration and development (on the example of fields in Western Siberia). Cand. Diss.]. Tyumen, 2006. 200 p.

13. Petersile V.I. K voprosu otsenki parametrov perekhodnoy zony s ispolzovaniem krivykh kapillyarnogo davleniya: sovershenstvovanie metodiki razvedki neftyanykh i gazovykh mestorozhdeniy [On the issue of estimating the parameters of the transition zone using capillary pressure curves: improving the methodology of oil and gas field exploration]. Trudy VNIGNI, 1982, no. 242, pp. 63-70.

14. Zakrevskiy K.E. Geologicheskoe 3D modelirovanie [Geological 3D modeling]. Moscow, OOO «IPCz Maska», 2009. 376 p

15. Zaboeva A.A. Razrabotka metodik trekhmernogo geomodelirovaniya $\quad$ v usloviyakh neodnorodnosti $i$ neravnomernosti geologogeofizicheskoy informatsii (na primere mestorozhdeniy Zapadnoy Sibiri). Dis. Kand. nauk [Development of methods for three-dimensional geomodeling in conditions of heterogeneity and non-uniformity of geological and geophysical information (on the example of deposits in Western Siberia). Cand. Diss.]. Tyumen, 2012. 167 p.

16. Yurev A.V. Sovershenstvovanie metodov opredeleniya filtratsionno-emkostnykh svoystv porod-kollektorov s primeneniem polnorazmernogo kerna (na primere ryada mestorozhdeniy severa Tima- 
no-Pechorskoy neftegazonosnoy provintsii). Dis. Kand. nauk [Improvement of methods for determining the filtration and reservoir properties of reservoir rocks using a full-size core (on the example of a number of fields in the north of the Timan-Pechora oil and gas province). Cand. Diss.]. Perm, 2019. 122 p.

17. Rassas A., Ren S., Sun R., Zafar A., Moharam S., Guan Z., Ahmed A., Alomaisi M. Application of 3D reservoir geological model on Es1 formation, Block Nv32, Shenvsi Oilfield, China. Open Journal of Yangtze Oil and Gas, 2020, vol. 5, no. 2, pp. 54-72.

18. Xiang Li. Three-dimensional geological modeling methods and applications - a gold belt oilfield. $3^{\text {rd }}$ International Conference on Management, Education, Information and Control (MEICI). Jinan, China, 2015. pp. 3-10.

19. Doych K.V. Geostatisticheskoe modelirovanie kollektorov [Geostatistical modeling of reservoirs]. Moscow, Izhevsk, Computer research Institute Publ., 2011. 400 p.

20. Gao Xingjun. Applied research of NMR movable fluid saturation in development of low permeability oilfield. E3S Web of Conferences 165, 01001, 2020, pp. 1-7.

21. Kuiqian Ma. Techniques for improving the water-flooding of oil fields during the high water-cut stage. Oil \& Gas Science and Technology - Rev. IFP Energies Nouvelles, 2019, vol. 74, pp. 1-12.

22. Juan Wang, Wei Liu, Wenwu Chen, Xuebin Ran, Yanfang Zhang, Gaochao Lin. An improved method for quantifying liquid saturation using transparent soil. Advances in civil engineering, 2019, vol. 1, pp. 1-11.

23. Buckley S.E., Leverett M.C. Mechanism of fluid displacement in sands. Transactions of The American Institute of Mining, Metallurgical and Petroleum Engineers, 1942, vol. 146, pp. 107-116.

24. Leverett M.C. Capillary behavior in porous solids. Transactions of the American Institute of Mining, Metallurgical and Petroleum Engineers, 1941, vol. 142, pp. 148-152.

Inaormation about the authors

Valentina A. Belkina, Cand. Sc., associate professor, Tyumen Industrial University.

Yaroslav O. Antipin, applicant Cand. Sc., Tyumen Industrial University.

Alexandra A. Zaboeva, Cand. Sc., associate professor, Tyumen Industrial University.
25. Li Kewen. Theoretical development of the brooks-corey capillary pressure model from fractal modeling of porous media. Symposium on Improved Oil Recovery, Tulsa, Oklahoma, 17-21 April, 2004. pp. 3-9.

26. Akhmetov R.T., Kuleshova L.S., Mukhametshin V.V. Application of the Brooks-Corey model in the conditions of lower cretaceous deposits in terrigenous reservoirs of Western Siberia. IOP Conference Series: Materials Science and Engineering, 2018, vol. 560, pp. 4-12.

27. Bozhenyuk N.N. Metody adaptatsii i snizheniya i neopredelennostey pri geologo-gidrodinamicheskom modelirovanii terrigennykh kollektorov na primere ryada mestorozhdeniy Zapadnoy Sibi$r i$. Dis. Kand. nauk [Methods of adaptation and reduction of uncertainties in geological and hydrodynamic modeling of terrigenous reservoirs on the example of a number of fields in Western Siberia. Cand. Diss.]. Tyumen, 2018. $172 \mathrm{p}$.

28. Elshahawi H., Fathy K., Hiekal S. Capillary pressure and rock wettability effects on wireline formation tester measurements. IEOC 567121999 SPE Annual Technical Conference and Exhibition. Houston, Texas, 1999. pp. 1-16.

29. Sankova N.V., Doroshenko A.A., Belkina V.A. Discretecontinuous models in the problem of forecasting fluid-dynamic characteristics of reservoirs. Nauka i TEK, 2012, no. 3, pp. 44-47. In Rus.

30. Tikhomirova E.A., SagirovaL.R., Khaibullina K.Sh. A review on methods of oil saturation modelling using IRAP RMS. IOP Conf. Series: Earth and Environmental Science, 2019, vol. 378, pp. 1-6.

Received: 25 August 2021. 